\title{
Evaluation of Quorum Quenching and Probiotic Activity of Bacillus thuringiensis QQ17 Isolated from Fish Culture Pond
}

\author{
Divya V. Haridas ${ }^{1,2^{*}}$ and Devika Pillai ${ }^{1}$ \\ ${ }^{1}$ Kerala University of Fisheries and Ocean Studies, Department of Aquatic Animal Health \\ Management, Centre for Aquatic Animal Health, Panangad P.O., Kochi, Kerala, \\ India, Pin- 682506 \\ ${ }^{2}$ Mahatma Gandhi University, School of Biosciences, Kottayam, Kerala, India, Pin- 686560 \\ *Corresponding author
}

\section{Keywords}

Quorum sensing, Quorum quenching, $\mathrm{N}$-acyl-homoserine lactones, Probiotic, Bacillus thuringiensis

Article Info

Accepted:

15 April 2019

Available Online:

10 May 2019

\section{A B S T R A C T}

This work was aimed at isolating AHL degrading bacteria from fish culture pond soil, with abilities appropriate for use as probiotic in aquaculture. The presence of an autoinducer inactivation (aiiA) homologue gene and AHL-inactivation assay showed that BacillusthuringiensisQQ17, which was one among the 20 isolates, could rapidly degrade synthetic C6-HSL in vitro and hampered violacein production by Chromobacterium violaceum. It had excellent biodegrading ability of natural N-AHL produced by Aeromonas hydrophila, suggesting that it can be used as a potential quencher bacterium for inhibiting the virulence of A. hydrophila. The isolate grew well at $\mathrm{pH} 3.0-7.0$, was resistant to high level of bile salts (0-0.9\%) and $0.5 \%$ of phenol. QQ17 also exhibited high degree of auto-aggregation and co-aggregation, confirming that it possessed good probiotic attributes. It was susceptible to all the 11 antibiotics tested and exhibited antagonistic activity against $A$. hydrophila. Gold fish fed diet incorporated with $10^{8}$ and $10^{10} \mathrm{CFU} / \mathrm{g}$ of the QQ17 for 30 days showed 73.33-83.33\% survival when challenged with pathogenic $A$. hydrophila. The study indicates that the isolate $B$. thuringiensis QQ17 could be used as a non- antibiotic feed additive in aquaculture to control bacterial diseases.

\section{Introduction}

Aquaculture is the rapidly expanding foodmanufacturing sector in the world. However, the industry is hindered by unforeseeable mortalities, many of which are generated by infectious microorganisms. The intensive fish farming has led to sudden occurrence of various bacterial diseases, necessitating the use of antibiotics in health management policies (Fyzuland Austin, 2014). In the beginning, use of antibiotic had been an effective strategy, but the indiscriminate use resulted in the emergence of antibiotic resistance in fish pathogens and in the transfer of these resistance genes to bacteria of terrestrial animals and to human pathogens (Verschuere et al., 2000). In addition to this, there is a high risk of antibiotic residues in human food. These unfavourable 
circumstances prompted aquaculture researchers to develop sustainable and ecofriendly approaches that are as equally functional as antibiotics (Standen et al., 2013) in controlling diseases. One such strategy is to impede with the bacterial signaling pathways controlling the production of virulence factors.

It is evident that bacterial pathogenicity relies on the quorum sensing (QS) process, where gene expression is mediated by extracellular signaling molecules called autoinducers (AIs). Autoinducers like $\mathrm{N}$-acyl-homoserine lactones (AHLs) are responsible for the regulation of virulence genes expression in many Gram-negative pathogenic bacteria (Federle and Bassler, 2003). Quorum quenching (QQ) is the mechanism of intercepting QS by inactivating signaling molecules. This is achieved by small molecule antagonists or signal degrading enzymes and has been considered as a unique approach to attenuate pathogenic bacteria (Dong et al., 2000; De foirdt et al., 2007). Quorum quenching enzymes, consisting lactonase, acylase, oxidoreductase and paraoxonase, have been recognized in quorum sensing and non-quorum sensing microbes (Dong et al., 2001; Lin et al., 2003).

As a more sustainable substitute to antibiotic, the use of probiotic is gaining acceptance for the control of bacterial pathogens in aquaculture too. Probiotics eliminate pathogens by competition process and have several mechanisms that provide health benefits to the host. These beneficial microorganisms have been discovered, characterized and used in aquaculture during the last three decades. In this context, application of signal degrading (quorum quenching) bacteria that can at the same time act as probiotic would be a unique dual strategy to control antibiotic-resistant pathogens and to support the host in a positive manner. Recently, some research works have been reported in quorum quenching bacteria isolated from gastrointestinal tract of aquatic animals (Nhan et al., 2010; Ramesh et al., 2014). It has also been shown that probiotic bacteria such as Enterococcus durans and Bacillus spp. inactivate the signal molecules of pathogenic bacteria by enzymatic action (Chu et al., 2010; Boopathi et al., 2017).

Bacillus thuringiensis is a spore forming soil bacterium that naturally synthesizes insecticidal proteins and has been used for insect control. They also occur in surfaces of leaf, aquatic environments, animal fecal matters, insect-rich environments etc. It has been proven that many of the strains of B.thuringiensisproduce AHL-inactivating enzymes and possesses quorum quenching activity (Dong et al., 2001). Recently, studies on the antagonistic and anthelmintic effect of $B$. thuringiensis strains against fish pathogens have also been reported (Bagde $e t$ al., 2009; Luis et al., 2016). The study of Chang et al., (2012) demonstrating the probiotic potential of $B$. thuringiensis isolated from cow milk is one of the very few studies that looked at the probiotic properties of the bacteria. The aim of this work was to study the quorum quenching attributes and probiotic properties of $B$. thuringiensis strain isolated from fish culture pond and to explore its potential use as a suitable biocontrol agent in aquaculture. This could be a dual strategy to control bacterial disease in aquaculture and thus, prevent the indiscriminate use of antibiotics.

\section{Materials and Methods}

\section{Bacterial strains and growth conditions}

CV026, a mini-Tn5 mutant derived from Chromobacterium violaceum was used as a biosensor to find out the presence of exogenous AHLs (C6-HSL). It was purchased 
from Microbial Culture Collection (MCC), NCCS, Pune. CV026 cannot synthesize AHL, but it can detect and respond to exogenous AHLs with acyl chain of four to eight carbons, by production of the purple coloured violacein pigment. CV026 strain was grown in Luria-Bertani (LB) medium at $28^{\circ} \mathrm{C}$ supplemented with $50 \mu \mathrm{gmL}^{-1}$ of kanamycin. The target fish pathogen Aeromonas hydrophila used in this study was provided by the National Bureau of Fish Genetic Resources (ICAR, Kochi, India). It was grown in LB broth (pH $7.2 \pm 0.2)$ at $150 \mathrm{rpm}$ overnight at $30^{\circ} \mathrm{C}$. Escherichia coli $\mathrm{DH} 5 \alpha$, (Promega) also grown in LB medium at $37^{\circ} \mathrm{C}$, served as negative control in AHLinactivation assay. All media used for AHLs assay were buffered with $50 \mathrm{mmolL}^{-1} 3-[\mathrm{N}$ morpholino] propane sulfonic acid (MOPS) to $\mathrm{pH} 6.8$, to prevent spontaneous degradation of AHLs.

Isolation and identification of quorum quenching bacteria from fish culture ponds

Soil samples were collected from tilapia culture ponds located on the campus of the Kerala University of Fisheries \& Ocean Studies (KUFOS), Kerala, India. A soil suspension was prepared in sterile physiological saline [(pH 7.4) $0.85 \% \mathrm{NaCl}]$. Samples were then enriched in minimal medium (KG medium) with AHL as the sole source of carbon and nitrogen. $100 \mu \mathrm{L}$ of the soil suspension was inoculated into $100-\mathrm{mL}$ flask containing $10 \mathrm{~mL}$ of $\mathrm{KG}$ medium $(\mathrm{pH}$ 6.8) with $500 \mu \mathrm{g} \mathrm{L}^{-1}$ of C6-HSL, as previously described (Chan et al., 2009) and incubated at $30^{\circ} \mathrm{C}, 150 \mathrm{rpm}$. After $24 \mathrm{hr}, 1 \mathrm{~mL}$ of culture was transferred to fresh C6-HSL containing KG medium for enrichment culturing. At the third-time enrichment cycle, a diluted soil suspension was plated onto LB agar. Pure colonies were obtained by repeated streaking on LB agar. The Selected bacterium was identified following Bergey's Manual of
Systematic Bacteriology (Ludwig et al., 2009)in accordance with different biochemical and physiological characteristics. Species level identification was carried out by 16S rDNA sequencing (SciGenom Labs, India) using universal primers $27 \mathrm{~F}$ and $1492 \mathrm{R}$ and analyzed using NCBI nucleotide database.

\section{Screening of quorum quenching activity}

\section{PCR amplification of aiiA homologue gene}

Initially, the quorum quenching activity of all isolates was checked by screening for the presence of aiiA (Autoinducer inactivation homologue) gene by PCR. Total DNA was extracted using HiPurA bacterial genomic DNA purification Kit (Himedia, India). The forward and reverse primers used were aiiA $F$ (5'-ATGGGATCCATGACAGTAAAGAAG CTTTAT-3') and aiiAR(5'GTCGAATTCCTCAACAAGATACTCCTA -ATG-3') respectively. PCR amplification was performed in a thermal cycler (MJ MINI, Biorad, USA), in $0.2 \mathrm{~mL}$ reaction tube consisting of $25 \mu \mathrm{L}$ total reaction volume containing $9 \mu \mathrm{L}$ nuclease free water, $12.5 \mu$ LGoTaq ${ }^{\circledR}$ Colorless Master Mix $2 \mathrm{X}$ (Promega, USA), $1.25 \mu \mathrm{L}(10 \mu \mathrm{M})$ of each primer and $1 \mu \mathrm{L}$ of template DNA (100ng). The reaction consisted of an initial denaturation of $94^{\circ} \mathrm{C}$ for $10 \mathrm{~min}$, followed by 30 cycles of $94^{\circ} \mathrm{C}$ for $30 \mathrm{~s}, 52^{\circ} \mathrm{C}$ for $30 \mathrm{~s}$, $72^{\circ} \mathrm{C}$ for $1 \mathrm{~min}$ and a final extension of $72^{\circ} \mathrm{C}$ for 5 min. Samples electrophoresed in 1.5\% agarose gel at $70 \mathrm{~V}$ were visualized using gel documentation system (Biorad, USA).

\section{Whole-cell AHL inactivation assay}

The whole-cell AHL inactivation assay was carried out as previously reported (Chan et al., 2007) with minor modifications. Briefly, randomly selected quorum quenching isolate (isolate showing the presence of aiiA 
homologue gene) grown overnight at $30^{\circ} \mathrm{C}$ in LB medium was centrifuged at 5000rpm for $10 \mathrm{~min}$ at $4^{0} \mathrm{C}$. Cell pellet was washed two times in $100 \mathrm{mM}$ PBS (pH 6.8) and resuspended in the same buffer to get OD600 of 1.0 (BIOPHOTOMETER, Eppendorf, Germany). $10 \mu \mathrm{g} \mu \mathrm{L}^{-1} \mathrm{C} 6-\mathrm{HSL}$ (a synthetic AHL, Sigma-Aldrich, India) in absolute ethanol was transferred to sterile micro centrifuge tube and dried by evaporation under aseptic conditions. The cell suspension in PBS was added to rehydrate AHL to the final concentration of $0.1 \mu \mathrm{g} \mu \mathrm{L}^{-1}$. The mixture was incubated at $30^{\circ} \mathrm{C}$ with gentle shaking for $12 \mathrm{hr}$. C6-HSL inactivation was assessed at $3 \mathrm{hr}$, 6hr and $12 \mathrm{hr}$ using CV026 as biosensor. Heat-denatured reaction mixture $(10 \mu \mathrm{L})$ at above mentioned time periods was loaded into the well of LB agar bioassay plate overlaid with the biosensor CV026 and incubated at $28^{\circ} \mathrm{C}$ for $24 \mathrm{hr}$. E. coli strain DH5 $\alpha$ served as negative control. Absence of violacein (purple zone) shown by CV026 indicated AHL degradation.

\section{AHL degradation with culture supernatant}

To find out whether the quorum quenching factor is released out of the cell or is bound to cell, an in vitro assay was carried out as previously described by Chu et al (2010) with minor modification. The isolate QQ17 grown overnight at $30^{\circ} \mathrm{C}$ in $\mathrm{LB}$ medium was centrifuged for $10 \mathrm{~min}$ at $7000 \mathrm{rpm}$ and the filter-sterilized supernatant of the overnight culture was taken for testing the AHL degrading activity. $100 \mu \mathrm{L}$ of the supernatant was mixed with an equal volume of $100 \mathrm{mM}$ PBS (pH 6.8) containing $0.2 \mu \mathrm{g} \mu \mathrm{L}^{-1}$ C6-HSL. Following that, the reaction mixture was incubated at $30^{\circ} \mathrm{C}$ for $24 \mathrm{hr}$ with gentle shaking, followed by incubation at $95^{\circ} \mathrm{C}$ for 5 min to stop the reaction. $10 \mu \mathrm{L}$ of the reaction mixture was loaded into the well of a LB agar plate seeded with the biosensor CV026 and incubated at $28^{\circ} \mathrm{C}$ for $24 \mathrm{hr}$.
Degradation of N-AHL produced by Aeromonas hydrophila

Fish pathogen A.hydrophila was inoculated in $10 \mathrm{~mL} \mathrm{LB}$ medium and incubated at $30^{\circ} \mathrm{C}$ for $24 \mathrm{hr}$. Bacterial cells were removed by centrifugation at $12000 \mathrm{rpm}$ for $5 \mathrm{~min}$ at $4^{\circ} \mathrm{C}$. Filter sterilized cell free culture supernatant was added to equal volume of fresh LB medium and QQ17 was inoculated in this medium. Bacterial culture was incubated at 30 ${ }^{\circ} \mathrm{C}$ for $48 \mathrm{hr}$ and AHL inactivation was assessed at $0 \mathrm{hr}$ and $48 \mathrm{hr}$ using CV026 as biosensor.

\section{Screening of probiotic activity}

\section{Bile salt and acid tolerance}

The isolate QQ17 was tested for bile salt tolerance and survival in acidic condition. Bacterial strain was grown overnight in LB media and $0.1 \mathrm{~mL}$ of culture suspension was inoculated into tubes containing $10 \mathrm{~mL}$ of autoclaved LB media with $0 \%, 0.3 \%, 0.6 \%$, and $0.9 \%$ bile salt (Himedia, India). The inoculated tubes were incubated at $30^{\circ} \mathrm{C}$ for $18 \mathrm{hr}$ and the absorbance at $600 \mathrm{~nm}$ was measured to evaluate growth. To determine acidic tolerance of QQ17, $0.1 \mathrm{~mL}$ of actively grown overnight culture at $30^{\circ} \mathrm{C}$ in $\mathrm{LB}$ medium was transferred to autoclaved LB broth adjusted to $\mathrm{pH}$ 1-7 with $\mathrm{HCl}$ (Sigma, India), which were then incubated at $30^{\circ} \mathrm{C}$ for $18 \mathrm{hr}$ followed by measurement of absorbance at $600 \mathrm{~nm}$.

\section{Phenol tolerance assay}

To check the phenol tolerance, actively growing overnight culture of QQ isolate was inoculated into LB media with concentration of $0.2 \%$ and $0.5 \%$ phenol or without phenol. Cell growth of the isolate was evaluated after $18 \mathrm{hr}$ of incubation at $30^{\circ} \mathrm{C}$, by measurement of absorbance at $600 \mathrm{~nm}$. 


\section{Auto-aggregation and co-aggregation} assays

To evaluate the probiotic potential of QQ17, auto-aggregation and co-aggregation rate were measured according to DelRe et al., (2000) with some modifications. Isolate was grown for $18 \mathrm{hr}$ at $30^{\circ} \mathrm{C}$ in LB media. The cells were harvested by centrifugation at 5000 rpm for $15 \mathrm{~min}$ at $4^{0} \mathrm{C}$, washed twice with PBS (pH 7.2) and resuspended in the same buffer. Absorbance $\left(\mathrm{A}_{600} \mathrm{~nm}\right)$ was adjusted to 0.2 in order to give viable counts of approximately $10^{8} \mathrm{CFU} \mathrm{ml^{-1 }}$.

Cell suspension (5ml) was mixed by vortexing for $10 \mathrm{~s}$ and the same suspension was left to rest for $5 \mathrm{hr}$ at room temperature without vortexing. Auto-aggregation of cell suspension was determined by taking $0.1 \mathrm{ml}$ of the upper suspension at every $1 \mathrm{hr}$ interval to another tube with $4.9 \mathrm{ml}$ of PBS and the absorbance of suspension at $600 \mathrm{~nm}$ was recorded. Cell auto-aggregation was measured by decrease in absorbance and autoaggregation percentage is demonstrated as: 1$(A t / A 0) \quad X \quad 100$, where $A t$ represents the absorbance at time $t=1,2,3,4$ or $5 \mathrm{hr}$ and $A_{0}$ the absorbance at $t=0$.

The method for preparing the cell suspension for co-aggregation was the same as that for auto-aggregation assay. QQ isolate prepared as described above was mixed with equal volume $(2 \mathrm{ml})$ of the culture of fish pathogen A.hydrophila and incubated at room temperature without agitation.

In control tubes, $4 \mathrm{ml}$ of each bacterial suspension alone was added. After $5 \mathrm{hr}$ of incubation, the absorbance (A) at $600 \mathrm{~nm}$ of the suspensions was measured. Coaggregation percentage was calculated using the equation of Handley et al (1987). Coaggregation $\%=\left[\left(A_{\text {pathog }}+A_{Q Q}\right) / 2-\left(A_{\text {mix }}\right)\right.$ $\left./\left(A_{\text {pathog }}+A_{Q Q}\right) / 2\right] \times 100$, where $A_{\text {pathog }}$ and
$A_{Q Q}$ constitute the absorbance in the tubes containing solely the pathogen or the quorum quenching bacteria (control tubes) respectively, and $A_{m i x}$ represents the absorbance of the mixture.

\section{Antibiotic sensitivity test}

Antibiotic susceptibility test was performed by disc diffusion method as stated by the guidelines of the Clinical and Laboratory Standard Institute (CLSI, 2002). Antibiotic discs (Himedia, India) were placed onto freshly plated QQ17 on the Muller-Hinton agar (Himedia, India) and antibiotic resistance was determined by measuring the diameter of the inhibition zone after incubation of the plate at $30^{\circ} \mathrm{C}$ for $18 \mathrm{hr}$. The antibiotic discs used in this test included ampicillin $(10 \mu \mathrm{g})$, amikacin $(30 \mu \mathrm{g})$, erythromycin $(15 \mu \mathrm{g})$, gentamycin $(10 \mu \mathrm{g})$, neomycin $(30 \mu \mathrm{g})$, penicillin $\mathrm{G}(10 \mathrm{U})$, kanamycin $(30 \mu \mathrm{g})$, streptomycin $(10 \mu \mathrm{g})$, oxacillin $(1 \mu \mathrm{g})$, vancomycin $(30 \mu \mathrm{g})$ and tetracycline $(30 \mu \mathrm{g})$.

\section{Antagonism test}

Agar well-diffusion method was carried out according to Schillinger and Lucke (1987) with some modification, to detect the in vitro antagonistic effect of the QQ17 against fish pathogen A. hydrophila. $100 \mu \mathrm{L}$ of fresh, actively growing pathogen was spread on Mueller-Hinton agar plate. Well with a diameter of $6 \mathrm{~mm}$ was prepared aseptically and cell free supernatant of actively growing QQ bacterial culture $(75 \mu \mathrm{L} /$ well $)$ was loaded into the well.

Plate was incubated at $30^{\circ} \mathrm{C}$ for $24 \mathrm{hr}$ and the zone diameter of inhibition (ZDI) was recorded. Inhibition zone of more than $20 \mathrm{~mm}, 10$ to $20 \mathrm{~mm}$, and less than $10 \mathrm{~mm}$ was considered as strong, intermediate, and low antimicrobial activity, respectively. 


\section{In vivo study}

\section{Maintenance of experimental fish}

To confirm the probiotic activity of QQ17, in vivo study was carried out. Fingerlings of goldfish Carassius auratus (Linnaeus, 1758) of uniform size were initially acclimatized in fibre reinforced plastic tanks of $300 \mathrm{~L}$ capacity for three weeks before starting the experiment. The fish were healthy, exhibited no symptoms of disease (tested through the examination of gills, fins and skin). The pathogen-free status of the fish was also confirmed by standard bacteriological examination procedures in the laboratory. During this period, a commercial fish feed was given to fish twice daily. All tanks were provided with proper aeration and water temperature was maintained at $26 \pm 1^{\circ} \mathrm{C}$.

\section{Safety of the QQ17}

The pathogenicity of the QQ17 was also ascertained before preparing probiotic feed. Two groups of six gold fish (3.34-4.32 g weight and 85.35-94.40 mm length), were challenged with $0.1 \mathrm{~mL}$ of PBS with $1.0 \mathrm{x}$ $10^{7}$ cells and $1.0 \times 10^{10}$ cells of QQ17 respectively by intraperitoneal injection. Gold fish in control group were injected with $0.1 \mathrm{~mL}$ of PBS. Fish were observed for mortality for seven days. During this period behaviour of fish was recorded daily. Before conducting the challenge study, the infectious dose of $A$. hydrophila was also determined by $50 \%$ lethal dose $\left(\mathrm{LD}_{50}\right)$ determination.

\section{Preparation of probiotic feed}

The probiotic feed was prepared by inoculating the QQ isolate in LB broth and incubated at $30^{\circ} \mathrm{C}$ for $24 \mathrm{~h}$. The cells were harvested by centrifugation at $3000 \mathrm{rpm}$ for $15 \mathrm{~min}$ at $4^{0} \mathrm{C}$, washed twice with PBS (pH 7.2) and resuspended in the same buffer.
Afterwards, the concentration of bacterial culture was adjusted to different cell densities $\left(10^{4} \mathrm{CFU}, 10^{6} \mathrm{CFU}, 10^{8} \mathrm{CFU} \& 10^{10} \mathrm{CFU}\right.$ per $\mathrm{mL}$ ) using a spectrophotometer (Hach- DR 6000 , Germany) and the suspension was added at the rate of $1 \mathrm{~mL}$ of culture $/ \mathrm{g}$ of feed to incorporate $10^{4}$ cells/g feed, $10^{6}$ cells $/ g$ feed, $10^{8}$ cells/g feed \& $10^{10}$ cells/g feed respectively. A binder (Brand: Aqua one, Salem Microbes Private limited, India) was used @1mL/10g feed. Binder alone was added in control feed. After proper mixing of the ingredients, the feeds were air dried and stored in screw capped glass bottles at room temperature until used. To ensure a required probiotic level in the supplemented feed, new probiotic diets were made on a weekly basis. Five groups of 10 gold fish each, C.auratus were introduced into five glass tanks of $50 \mathrm{~L}$ capacity. Four groups were fed with $10^{4} \mathrm{CFU}$, $10^{6} \mathrm{CFU}, 10^{8} \mathrm{CFU}$ and $10^{10} \mathrm{CFU} / \mathrm{g}$ of probiotic diet respectively, while the fifth group was maintained as control group. Feeding was done two times daily at the rate of $3 \%$ of the body weight of $C$. auratus for 30 days. Continuous aeration and water flow were maintained in all glass tanks. During the study period, activity and behaviour of the fish were monitored and recorded daily.

\section{Bacterial challenge study}

All fish were clinically healthy before challenge. Control and probiotic fed fish were challenged (10nos/group) via intraperitoneal injection with $0.1 \mathrm{~mL}$ of $1 \times 10^{6}$ cells $\left(\mathrm{LD}_{50}\right.$ based on preliminary work) of A.hydrophila. The fish were observed to determine mortality, external signs of infection and behavioural abnormalities for two weeks. Dead fish were removed immediately for bacteriological examination. Bacterial isolation was carried out from hemorrhagic and ulcerative lesions, and from dead fish's visceral organs. 


\section{Statistical analysis}

All the experiments were performed in triplicate and the results were expressed as mean \pm standard deviation (SD) of triplicates. Data were statistically processed by one way ANOVA using SPSS (Version 21.0) to find out whether there was significant difference between the treatments in each of the experiment. Statistically significant differences were defined at $\mathrm{p}<0.01$.

\section{Results and Discussion}

\section{Isolation and identification of quorum quenching bacteria}

20 bacterial isolates in the $\mathrm{KG}$ medium containing C6-HSL were screened. Finally, one representative isolate showing strong AHL degrading activity was selected. It was characterized at the physiological, biochemical and morphology levels. Based on biochemical properties, the strain showed close resemblance to Bacillus spp. To further identify the strain, 16S rDNA sequencing was carried out. Results showed QQ isolate shared 99\% homology with B. thuringiensis species (GenBank accession number AE017355).

\section{Detection of aiiA homologue gene}

Autoinducer inactivation (aiiA) gene was found in Gram-positive bacterium $B$. thuringiensis QQ17. All the 20 bacterial isolates were screened for presence of aii Ahomologue gene by PCR and six bacteria with aii Ahomologue gene were observed. The expected amplicon size of approximately 800 base pairs was detected (Figure 1).

\section{Whole-cell AHL inactivation assay}

B. thuringiensis QQ17 that possessed aiiA homologue gene was selected for AHLinactivation assay. Almost all C6-HSL was degraded after incubating with QQ isolate for $6 \mathrm{hr}$ (Figure 2c), showing rapid AHL degradation. Only leftover C6-HSL was detected by CV026 when the reaction was ceased after incubation for $3 \mathrm{hr}$ (Figure 2b). No visible AHL degradation was noticed in DH5 $\alpha$ that served as negative control (Figure 2a). The supernatant of QQ17 had no AHLinactivating activity, and the diameter of the purple pigmented zone had no remarkable difference with that of negative control DH5a well (Data not shown). In order to confirm AHL degrading activity of QQ isolate, crude cell free culture supernatant of A.hydrophila as natural N-AHL was used instead of synthetic C6-HSL. Complete degradation of natural N-AHL after $48 \mathrm{hr}$ incubation with QQ17 was observed (Data not shown). No AHL degradation was observed and presence of violacein (purple zone) was shown by CV026 at $0 \mathrm{hr}$ incubation. This result also revealed the presence of natural N-AHL in crude cell free culture supernatant of A.hydrophila.

Bile salt, $\mathrm{pH}$ and phenol tolerance of $B$. thuringiensis QQ17

B. thuringiensis QQ17 grew successfully in all tested concentrations of bile (0-0.9\%) after $18 \mathrm{hr}$ of incubation. This data suggests that $B$. thuringiensis QQ17 is resistant to high bile salt concentration (Figure 3a). pH tolerance studies showed that B. thuringiensis QQ17 grew at $\mathrm{pH} 3$ or above but did not grow in conditions less than $\mathrm{pH} 3$ (Figure 3b). The isolate grew well at $0-0.5 \%$ of phenol in LB media (Figure 3c).

\section{Auto-aggregation and Co-aggregation assays}

The result showed that B. thuringiensis QQ17 had excellent auto-aggregation property [(81.94 $\pm 0.13 \%)$ (Figure 4)] and aggregation values increased with time. B. thuringiensis 
QQ17 also exhibited very good coaggregation ability after $5 \mathrm{hr}$ of incubation with A. hydrophila, during which $41.6 \pm 0.04 \%$ of QQ isolate was co-aggregated with A.hydrophlila (Data not shown).

Antibiotic resistance of
thuringiensisQQ17

Since antibiotic sensitive probiotics are most preferred, the in vitro antibiotic sensitivity/resistance of $B$. thuringiensis QQ17 to 11 antibiotics was checked. Results indicated that $B$. thuringiensis was susceptible to antibiotics such as ampicillin, amikacin, erythromycin, gentamycin, kanamycin, neomycin, oxacillin, penicillin $G$, streptomycin, tetracycline, and vancomycin (Table 1).

\section{Antagonism test}

B.thuringiensis QQ17 exhibited excellent antimicrobial activity against fish pathogen A.hydrophila (Figure 5) by producing growth inhibition zone of $26 \pm 0.22 \mathrm{~mm}$ diameter in agar well diffusion assay.

\section{Safety of the B.thuringiensis QQ17}

The administration of B.thuringiensisQQ17 even at the concentration of $1 \times 10^{10}$ cells/fish did not result in any unfavorable effect on fish activity. All fish were clinically healthy and behaved like control group. This result suggested that the isolate $B$. thuringiensis QQ17 is not virulent to fish.

\section{Experimental challenge with $A$. hydrophila}

The administration of QQ diet (B.thuringiensis) afforded effective protection against experimental $A$. hydrophila infection. In control group, following challenge with $A$. hydrophila, all fish showed severe skin lesions and $50 \%$ mortality was observed in two days. One fish each died in $10^{4} \mathrm{CFU} / \mathrm{g}$ feed and $10^{6} \mathrm{CFU} / \mathrm{g}$ feed in two days and majority of the fish in both these treatments showed mild skin lesions and haemorrhages. In contrast, during the same time, there was no mortality in the two groups fed with QQ diet of $10^{8} \mathrm{CFU} / \mathrm{g}$ feed and $10^{10} \mathrm{CFU} / \mathrm{g}$ feed (Merely one fish in $10^{8} \mathrm{CFU} / \mathrm{g}$ out of the entire lot of fish developed mild haemorrhages). At the end of two weeks, the highest survival rate was noticed in groups of fish fed with $10^{8} \mathrm{CFU} / \mathrm{g}(73.33 \%)$ and $10^{10}$ CFU/g (83.33\%) probiotic diet. ANOVA showed that there was significant difference $(p \leq 0.01)$ in the survival rates among different concentrations. Post Hoc analysis using Duncan's Multiple Range Test grouped the concentrations into three homogenous groups viz; (1) Control (had only $13.33 \%$ survival) (2) $10^{4} \mathrm{CFU} / \mathrm{g}$ and $10^{6} \mathrm{CFU} / \mathrm{g}$ probiotic feed (had $43.33 \%$ survival) and (3) groups fed with $10^{8} \mathrm{CFU} / \mathrm{g}\left(73.33 \%\right.$ survival) and $10^{10} \mathrm{CFU} / \mathrm{g}$ (83.33\% survival) (Table 2). A. hydrophila was isolated from haemorrhagic lesions of both dead and survived fish.

The present study focused on soil bacteria $B$. thuringiensis QQ17 that exhibited both probiotic and quorum quenching ability. To the best of our knowledge, there are hardly any reports demonstrating the probiotic activity of $B$. thuringiensis isolated from fish culture pond soil that possess AHL degrading activity. In this study, synthetic N-hexanoylL-homoserine lactone (C6-HSL) was used as a test compound. The AHL-degrading ability of isolated bacteria was initially screened by PCR amplification of aiiA gene. Previous studies by Dong et al (2000) revealed that the aiiAgene is responsible for AHL degradation in Bacillus sp. and is common among most Bacillus strains. As the presence of aiiAhomologue gene can only predict but does not confirm the AHL degrading function, the whole cell inactivation assay was also carried out and finally we selected 
B.thuringiensis QQ17, which synthesize AHL-degrading enzyme, based on its ability to stop AHL-dependent violace in production by the bio indicator CV026. In whole-cell in vitro AHL-inactivation assay, nearly all synthetic C6-HSL was degenerated after incubating with $B$. thuringiensis QQ17 for 6 $\mathrm{hr}$, indicating rapid and strong QQ activity. Similar result was observed in a study by Chu et al., (2010) in which the isolate QSI-1 (Bacillus spp.) degraded C6-HSL completely within $6 \mathrm{hr}$ in whole-cell AHL-inactivation assay. The supernatant of $B$. thuringiensis QQ17 could not inactivate C6-HSL, indicating that the degrading enzyme is not discharged out of the cell, that agrees with the reports by Molina et al., (2003) and Chu et al (2010), suggesting that the signaling molecules diffuse into the quorum quenching bacterial cells where molecule inactivation takes place. The efficacy evaluation of the B.thuringiensis QQ17 for degradation of natural N-AHL produced by A.hydrophila resulted in the complete inactivation of $\mathrm{N}$ AHL within $48 \mathrm{hr}$ of incubation. C4-HSL and C6-HSL are the major autoinducers produced by A.hydrophila(Swift et al., 1997) and can be detected by CV026. This result suggests that B.thuringiensis QQ17 can be used as potential quencher bacterium in aquatic environment very effectively for inhibiting the virulence of A.hydrophila.

The results of the present study showed that B.thuringiensis, in addition to possessing excellent quorum quenching properties, has very good probiotic properties such as bile salts, acid and phenol resistance, auto aggregation, co- aggregation, antibiotic sensitivity and growth inhibitory effect against fish pathogen A.hydrophila. Acid and bile tolerance are two inevitable properties that give a probiotic the potential to remains alive in the upper gastrointestinal tract, especially the acidic condition in the stomach and the presence of bile in the small intestine
(Erkkila and Petaja, 2000). In the present study, B. thuringiensis QQ17 tested for bile salt tolerance exhibited growth even in $0.9 \%$ bile salt at $18 \mathrm{hr}$ of incubation, suggesting that it has the capacity to withstand in fish as well as in human gut. Many reports are found to describe the bile salt tolerance of Bacillus sp. (Verschuere et al., 2000; Chang et al., 2012). Fish gastrointestinal $\mathrm{pH}$ shows great variation among species with a range of 1.47 to 5.12 and the lowest value observed was 1.18 (Welliton et al., 2017). However, such extreme low $\mathrm{pH}$ is transient. The $\mathrm{pH}$ value raises to 3 and above in the presence of food (Erkkila and Petaja, 2000). In the present study, we found that $B$. thuringiensisQQ17 grew at $\mathrm{pH} 3$ or above. These results suggest that the QQ isolate $B$. thuringiensis given as a probiotic diet will be able to survive the harsh conditions of the gut environment and colonize the intestinal tract, thereby will be capable of imparting their benefits. In this study the isolate could also grow and persisted well at $0.5 \%$ of phenol in LB media. Phenol may be synthesized in the intestine by bacterial deamination of various aromatic amino acids derived from dietary or endogenously derived protein (Suskovic et al., 1997). Studies on different animal models reveal that phenol has a bacteriostatic effect against gut bacteria (Hoier, 1992). Since probiotics should withstand the harsh gut environment, tolerance to phenol is considered as a mandatory probiotic property.

Auto-aggregation and co-aggregation properties are considered as major characteristics of probiotic bacteria. Assessment of auto-aggregation and potential to co-aggregate with harmful intestinal pathogens can be used for initial evaluation and selection of the best probiotic strain. In this study, the B.thuringiensis QQ17 exhibited high degree of auto-aggregation (81.94 $\pm 0.13 \%$ ) and co-aggregation activity $(41.6 \pm 0.04 \%)$. Auto-aggregation property is 
responsible for the bacterial adhesion on to the intestinal cell wall; an essential feature for a good probiotic strain (Bao et al., 2010). Coaggregation abilities of probiotics might become an obstacle that prevents colonization of pathogenic bacteria in the gastrointestinal tract (Garcia et al., 2014).

The antibiotic sensitivity of bacteria is another important property to be considered to formulate safe probiotic products for aquaculture applications. Now, overuse of antibiotics has become a serious health problem and has led to the emergence of a large number of antibiotic-resistant strains. Antibiotic resistance in probiotic bacteria may results in active transfer of antibiotic resistant genes from probiotics to other intestinal microflora and finally to opportunistic pathogens that reside in the same harsh environment. This may ultimately have serious clinical ramifications (Imperial and Ibana, 2016). In the present study, $B$. thuringiensis QQ17 showed susceptibility to all 11 antibiotics tested. This result supports the possibility of the isolate to be developed as probiotic. Recently, Chang et al (2012) isolated $B$. thuringiensis strain from cow milk that showed antibiotic susceptibility towards all tested antibiotics.

The concept of antagonism in probiotics against pathogenic bacteria has been well studied. The antibacterial property has been regarded as one of the important attributes in selecting potential probiotics for inhibiting the growth of pathogenic bacteria in the gut. The antagonistic activity of beneficial bacteria against pathogenic bacteria can be induced by the production of carbon dioxide, organic acids (mainly, lactic acids), hydrogen peroxide, acetoin, ethanol, reutericyclin, diacetyl, acetaldehyde, reuterin, antimicrobials such as bacteriocins (Jin, 1996). This activity, along with the process of competitive exclusion, in which probiotic bacteria fight against intestinal pathogens for food and attachment sites, would stop colonization of pathogenic bacteria in the gastrointestinal tract (Saulnier et al., 2009). In the present study, the agar well diffusion assay was used to find out the antagonistic effect of cell-free supernatant. B.thuringiensis QQ17 showed strong inhibitory effect towards the tested pathogen A.hydrophila. Earlier studies by Aly et al., (2008) showed the growth inhibition of $A$. hydrophila using a cell-free supernatant of three bacillus species that were used as probiotic. Probiotic isolates from the intestine of fresh water fishes showed inhibitory activity against pathogenic bacteria (Chemlal et al., 2012). Bagde et al., (2009) demonstrated antagonistic effect of Bacillus thuringiensis sub. Sp. $\mathrm{H} 12$ on pathogens from tilapia by agar well diffusion method.

Since the bacterial pathogen A. hydrophila is responsible for frequent disease occurrences observed in aquariums and ornamental fish culture, in the present work, we selected this bacterium for bacterial challenge study. The QQ isolate B. thuringiensis isolated in the present study had no harmful effect on goldfish and the probiotic diet supplemented with $10^{8} \mathrm{CFU}$ and $10^{10} \mathrm{CFU}$ for 30 days protected the fish when challenged with $A$. hydrophila. Lowest (13.33\%) survival was observed in the control (fed with basal diet) compared with probiotic fed groups. Highest survival of fish was recorded in the group fed with probiotic diet of $10^{10} \mathrm{CFU} / \mathrm{g}$ feed and $10^{8} \mathrm{CFU} / \mathrm{g}$ feed $(83.33 \%$ and $73.33 \%$ respectively). Statistical analysis showed that there was no significant difference in the survival rate between these two groups (post hoc analysis) suggesting that $10^{8} \mathrm{CFU} / \mathrm{g}$ may be sufficient to afford protection to the fish against $A$. hydrophila infection. These results were comparable to findings by Brunt and Austin (2005) where they used Aeromonas sorbia GC2 at a dose of $5 \times 10^{7}$ cells / $\mathrm{g}$ feed 
as feed additive to control infection caused by Lactococcus garvieae and Streptococcus iniae in rainbow trout and the untreated control experienced mortality of $75-100 \%$ when challenged with $L$. garvieae and S.iniae. The spore-forming bacterium, B. thuringiensis, is widely known as a bio insecticide which controls plant diseases. Previous studies have demonstrated that $B t$ is basically non-toxic and non-infectious to other living organisms like birds, fish, and shrimp (Perez et al., 2015). A great number of studies exist suggesting that feeding of Bacillus spp. significantly increases the resistance towards bacterial infection in tilapia (Ghosh et al., 2003) and brown trout (Balcazar et al., 2007).

Table.1 Antibiotic resistances of Bacillus thuringiensis QQ17

\begin{tabular}{|l|l|l|l|l|l|l|l|l|l|l|}
\hline \multicolumn{10}{|c|}{ Zone of growth inhibition diameter $(\mathbf{m m})$} \\
\hline AM & AN & E & GM & K & N & OX & P & S & TE & VA \\
\hline $19 \pm 0.48$ & $21 \pm 0.18$ & $30 \pm 0.22$ & $22 \pm 0.07$ & $24 \pm 0.88$ & $21 \pm 0.39$ & $17 \pm 0.03$ & $18 \pm 0.08$ & $24 \pm 0.25$ & $28 \pm 0.08$ & $22 \pm 0.38$ \\
\hline
\end{tabular}

Foot note: AM: ampicillin $(10 \mu \mathrm{g})$, AN: amikacin $(30 \mu \mathrm{g})$, E: erythromycin $(15 \mu \mathrm{g})$, GM: gentamycin $(10 \mu \mathrm{g}), \mathrm{K}$ :

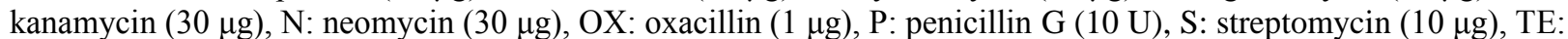
tetracycline $(30 \mu \mathrm{g})$, VA: vancomycin $(30 \mu \mathrm{g})$. The mean of three values of zone of growth inhibition of each antibiotic are presented along with $\pm S D$

Sensitive $\geq 20 \mathrm{~mm}$, Intermediate $15-19 \mathrm{~mm}$, Resistant $\leq 14$

Table.2 Survival percentages of Carassius auratus (fed with different concentration of probiotic diet) two weeks after the experimental infection with Aeromonas hydrophila by intraperitoneal injection

\begin{tabular}{|l|l|}
\hline $\begin{array}{l}\text { Probiotic } \\
\text { concentration }\end{array}$ & $\begin{array}{l}\text { Survival } \\
\%\end{array}$ \\
\hline Control & $13.33 \pm 5.8^{\mathrm{a}}$ \\
$1 \times 10^{4} \mathrm{CFU}$ & $43.33 \pm 5.8^{\mathrm{b}}$ \\
$1 \times 10^{6} \mathrm{CFU}$ & $43.33 \pm 5.8^{\mathrm{b}}$ \\
$1 \times 10^{8} \mathrm{CFU}$ & $73.33 \pm 5.8^{\mathrm{c}}$ \\
$1 \times 10^{10} \mathrm{CFU}$ & $83.33 \pm 5.8^{\mathrm{c}}$ \\
\hline
\end{tabular}

Foot note: Values are mean $\pm S D$ of triplicate observations. Values with different superscripts are significantly different $(\mathrm{p}<0.01)$.

Fig.1 PCR detection of aiiA homologue gene. Lane A: 100 bp DNA ladder (Promega); lane B-G: different isolates; lane H: negative control. Arrow shows the expected amplicon size of approximately 800 bp

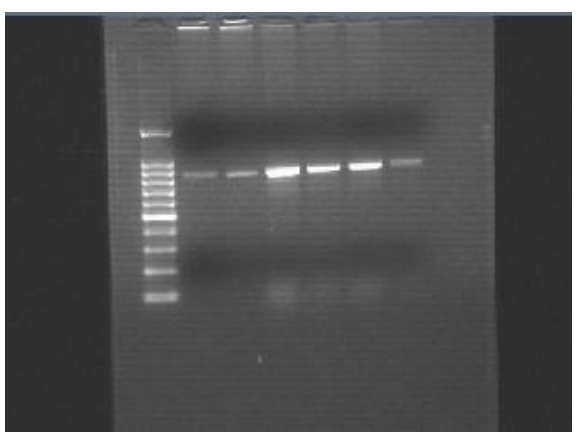


Fig.2 AHL-degrading activity of Bacillus thuringiensis QQ17. QQ isolate was incubated with C6-HSL for $3 \mathrm{hr}$ (2b), $6 \mathrm{hr}$ (2c) and $12 \mathrm{hr}$ (2d). (2a) Escherichia coli DH5a (negative control). Pigment formation indicates the presence of C6-HSL; degradation of C6-HSL is evident by loss of pigment formation on the biosensor lawn. QQ isolate, quorum-quenching isolate; AHL, acyl-homoserine lactone

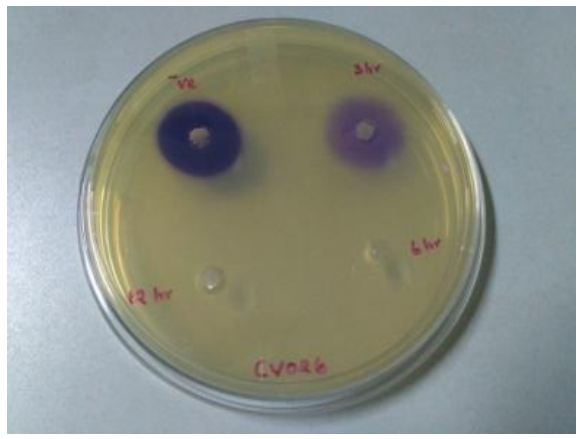

Fig.3a,b\&c Effect of bile salt (3a), pH (3b) and phenol (3c) on the growth of Bacillus thuringiensis QQ17 at 30oC. To check bile-salt, $\mathrm{pH}$ and phenol resistance, the growth of B.thuringiensis QQ17 in LB medium for $18 \mathrm{hr}$ was determined by measuring OD at $600 \mathrm{~nm}$ after adjusting the culture media to the specific $\mathrm{pH}$, salt and phenol concentration. Values are mean \pm SD of three different observations
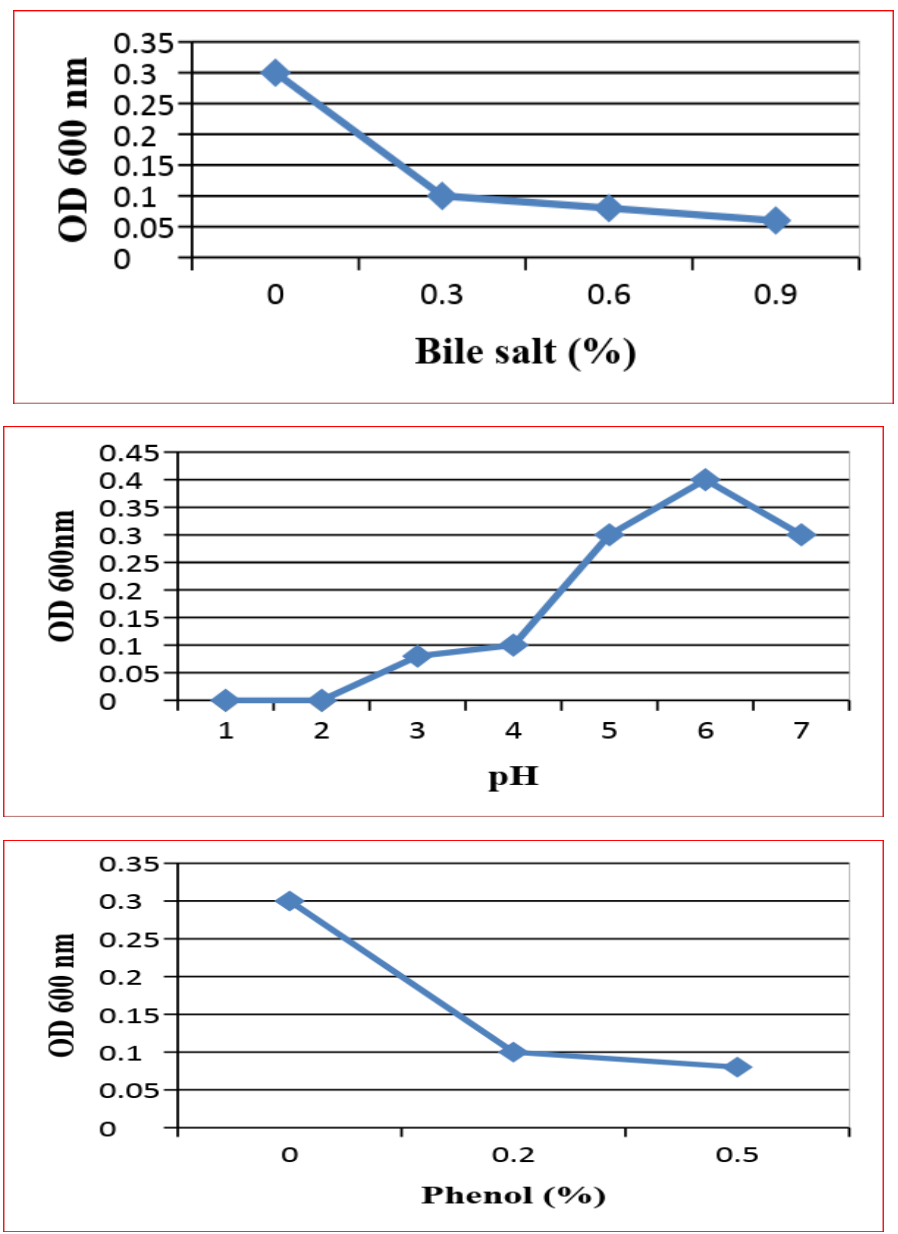
Fig.4 Auto-aggregation rate of quorum quenching isolate Bacillus thuringiensis QQ17. Aggregation percentage increased every $1 \mathrm{hr}$ and highest rate was observed at $5 \mathrm{hr}$

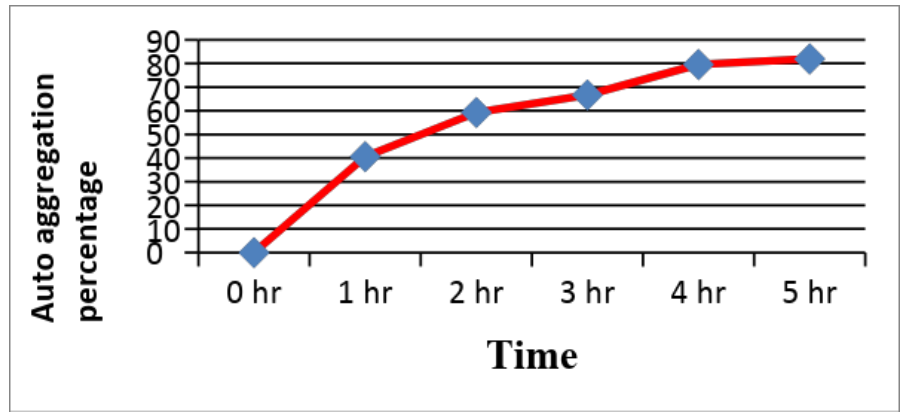

Fig.5 The agar well diffusion assay to determine the antagonistic activity of Bacillus thuringiensis QQ17. Zone of growth inhibition (26 \pm 0.22 diameter) indicates the antagonistic activity of cell free supernatant of $B$. thuringiensis QQ17 towards A. hydrophila. This value is the mean $\pm \mathrm{SD}$ of three different observations

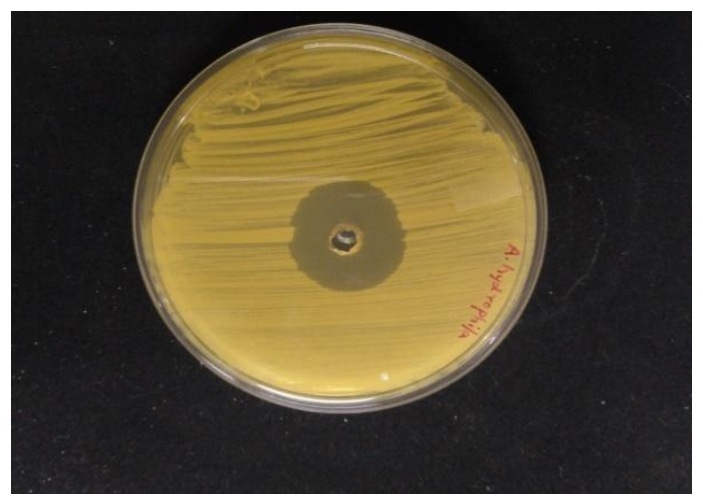

Recently, there are reports of quorum quenching probiotics that have the ability to change the intestinal microflora structure by degrading AHLs (Chu et al., 2010; Boopathi et al., 2017). The results of the present study clearly suggest that the significant increase in survival of goldfish after challenging with A.hydrophila is due to the combined effect of quorum quenching ability of $B$. thuringiensis QQ17 together with its probiotic activity. Production of AHL degrading enzyme might have inhibited the pathogenicity of A.hydrophila, while, the probiotic potential of the QQ isolate might have simultaneously helped to out-compete A.hydrophila for nutrients and space and exclude the pathogenic bacteria through antagonistic activity.

\section{Acknowledgement}

The authors thank the authorities of the Kerala University of Fisheries and Ocean Studies (KUFOS), Kochi, Kerala for the facilities extended for carrying out this work at the Centre for Aquatic Animal Health Management, KUFOS. We thank Dr. Mathew Sebastian, KUFOS for the statistical analysis of results.

\section{References}

Aly, S. M., Ahmed, Y. A., Ghareeb, A. A., and Mohamed, M. F. 2008. Studies on Bacillus subtilis and Lactobacillus acidophilus, as potential probiotics, on the immune response and resistance of 
Tilapia Nilotica (Oreochromis niloticus) to challenge infections. Fish and Shellfish Immunology, 25, 128 136.

Bagde, U.S., Bilolikar, B.V., and Pandit, R.S. 2009. Antagonistic effect of Bacillus thuringiensis sub-species (h12) on pathogens of tilapia species. Asian Journal of Microbiology, Biotechnology \& Environmental Sciences, 11,917-922.

Bandyopadhyay, P., and Mohapatra, P.K.D. 2009. Effect of a probiotic bacterium Bacillus circulans PB7 in the formulated diets: on growth, nutritional quality and immunity of Catlacatla (Ham.). Fish Physiology and Biochemistry, 35, 467-478.

Bao, Y., Zhang, Y., Zhang, Y., Liu, Y., Wang, S., Dong, X., Wang, Y., and Zhang, H. 2010. Screening of potential probiotic properties of Lactobacillus fermentum isolated from traditional dairy products. Food Control, 21,695-701.

Boopathi, S., Selvakumar, N., and Sivakumar,G. 2017. Quorum quenching potentials of probiotic Enterococcus durans Lab38 against methicillin resistant Staphylococcus aureus. Asian Journal of Pharmaceutical and Clinical Research, 10, 445-450.

Brunt, J.1., and Austin, B. 2005. Use of a probiotic to control lactococcosis and streptococcosis in rainbow trout, Oncorhynchus mykiss (Walbaum). Journal of Fish Disease, 28, 693-701.

Chan, K.G., Tiew, S.Z., and Ng, C.C. 2007. Rapid isolation method of soil bacilli and screening of their quorum quenching activity. Asia-Pacific Journal of Molecular Biology and Biotechnology, 15, 153-156.

Chan, K.G., Yin, W.F., Sam, C.K., and Koh, C.L. 2009. A novel medium for the isolation of $\mathrm{N}$-acylhomoserine lactone-degrading bacteria. Journal of Industrial Microbiology and Biotechnology, 36,247-251.

Chang, H. K., Sang, Y. C., Hyog, Y. K., Eun, H. K., Hyun, M. K., Jin, S. M., Geum, C. J., Hee, S. L., Seung, W. K., Jong, M. K., Suhkneung, P., and Dong, K. R. 2012. Isolation, characterization, and evaluation of Bacillus thuringiensis isolated from cow milk. Korean Journal of Veterinary Research, 52, 169-176.

Chemlal, K.F., Sahnouni, A., Matallah, B., and Boutiba, Z. 2012. The probiotic potential of lactobacilli isolated from Nile tilapia (Oreochromis niloticus)'s intestine. African Journal of Biotechnology, 11,13220-13227.

Chu, W., Lu, F., Zhu, W., and Kang, C. 2010. Isolation and characterization of new potential probiotic bacteria based on quorum-sensing system. Journal of Applied Microbiology, 110, 202-208.

Clinical and Laboratory Standards Institute (CLSI). Performance standards for antimicrobial disk and dilution susceptibility tests for bacteria isolated from animals; approved standards. 2nd ed. NCCLS document M32-A2, CLSI, Wayne, 2002.

Defoirdt, T., Boon, N., Sorgeloos, P., Verstraete, W., and Bossier, P. 2007. Alternatives to antibiotics to control bacterial infections: luminescent vibriosis in aquaculture as an example. Trends in Biotechnology, 25, 472-479.

Del Re, B., Sgorbati, B., Miglioli, M., and Palenzona, D. 2000. Adhesion, auto aggregation and hydrophobicity of 13 strains of Bifidobacterium longum. Letters in Applied Microbiology, 31, 438-442.

Dong, Y.H., Wang, L.H., Xu, J.L., Zhang, H.B., Zhang, X.F., and Zhang, L.H. 2001. Quenching quorum sensing 
dependent bacterial infection by $\mathrm{N}$ acyl homoserinelactonase. Nature, 411,813-817.

Dong, Y.H., Xu, J.L., Li, X.Z., and Zhang, L.H. 2000. AiiA, an enzyme that inactivates the acylhomoserine lactone quorum sensing signal and attenuates the virulence of Erwinia carotovora. Procedings of the National Academy of Sciences of the United States of America, 97, 3526-3531.

Erkkila, S., and Petaja, E. 2000. Screening of commercial meat starter cultures at low $\mathrm{pH}$ and in the presence of bile salts for potential probiotic use. Meat Science, 55, 297-300.

Federle, M.J., and Bassler, B.L. 2003. Interspecies communication in bacteria. Journal of Clinical Investigation, 112, 1291-9.

Fyzul, N.A.I., and Austin, B. 2014. Probiotics, immunostimulants, plant products and oral vaccines, and their role as feed supplements in the control of bacterial fish diseases. Journal of Fish Diseases, 38, 937-955.

Garcia,C.T., Korany, A.M., Bustos, I., Gomez de,C.L.P., Requena, T., and Pelaez, C.2014. Adhesion abilities of dairy Lactobacillus plantarum strains showing an aggregation phenotype. Food Research International, 57, 4450.

Ghosh, K., Sen, S. K., and Ray, A. K. 2003. Supplementation of an isolated fish gut bacterium Bacillus circulans, in formulated diets for Rohu, Labeorohita, fingerlings. The Israeli Journal of Aquaculture Bamidgeh, 55, 13-21.

Handley, P.S., Harty, D.W.S., Wyatt, J.E., Brown, C.R., Doran, J.P., and Gibbs, A.C.C. 1987. A comparison of the adhesion, co aggregation and cellsurface hydrophobicity properties of fibrillar and fimbriate strains of Streptococcus salivarius. Journal of General Microbiology, 133, 3207-3217.

Hoier, E. 1992. Use of probiotic starter cultures in dairy products. In: The 25th Annual Convention, Australian Institute of Food Science Technology, Sydney, Australia.

Imperial, I. C., and Ibana, J. A. 2016. Addressing the antibiotic resistance problem with probiotics: reducing the risk of its double-edged sword effect. Frontiers in Microbiology, 7, 1-10.

Jin, L.Z. 1996. Studies on the mechanisms and utilization of probiotics (direct-fed microbial) in broilers [Ph.D. thesis] Kuala Lumpur, University Putra Malaysia, Malaysia.

Lin, Y.H., Xu, J.L., Hu, J., Wang, S. L., and Ong, J.R. 2003. Acyl-homoserine lactone acylase from ralstonia strain XJ12B represent a novel and potent class of quorum quenching enzymes. Molecular Microbiology, 47,849-860.

Luis, J.M., Victor, M.H., Ivan, A.S., Fernando, I.F., Jorge, M.M., and Guadalupe, P.C. 2016. Anthelmintic Effect of Bacillus thuringiensis Strains against the Gill Fish Trematode Centrocestus formosanus. BioMedical Research International, 20, 1-9.

Molina, L., Constantinescu, F., Michel, L., Reimmann, C., Duly, B., and De fago, G. 2003. Degradation of pathogen quorum-sensing molecules by soil bacteria: a preventive and curative biological control mechanism. FEMS Microbiology Ecology, 45, 71-81.

Nhan, D.T., Cam, D.T.V., Wille, M., Defoirdt, T., Bossier, P., and Sorgeloos, P. 2010. Quorum quenching bacteria protect Macrobrachium rosenbergii larvae from Vibrio harveyi infection. Journal 
of Applied Microbiology, 109, 10071016.

Perez, J., Bond, C., Buhl, K., and Stone, D. 2015. Bacillus thuringiensis (Bt) General Fact Sheet. National Pesticide Information Center, Oregon State University Extension Services. Retrieved from http://npic.orst.edu/factsheets/btgen.ht $\mathrm{ml}$.

Ramesh, K., Natarajan, M., Sridhar, H., Uma Vanitha, M., and UmaMaheswar, S. 2014. Feasibility of shrimp gut probionts with anti-vibrio and anti-QS in penaeid culture. International Journal of Fisheries and Aquatic Studies, 51, 26-34.

Saulnier, D.M., Spinler, J.K., Gibson, G.R., and Versalovic, J. 2009. Mechanisms of probiosis and prebiosis: considerations for enhanced functional foods. Current Opinion in Biotechnology, 20, 135-41.

Schillinger, U., and Lucke, F.K. 1987. Identification of lactobacilli from meat and meat products. Food Microbiology, 4,199-208.

Standen, B.T., Rawling, M.D., Davies, S.J., Castex, M., Foey, A., and Gioacchini, G. 2013. Probiotic Pediococcus acidilactici modulates both localised intestinal and peripheral immunity in tilapia (Oreochromis niloticus). Fish and Shellfish Immunology, 35, 1097104.

Suskovic, J., Brkic, B., Matosic, S., and Maric, V. 1997. Lactobacillus acidophilus M92 as potential probiotic strain. Milk science international, 52, 430-435.

Swift, S.1., Karlyshev, A.V., Fish, L., Durant, E.L., Winson, M.K., Chhabra, S.R., Williams, P., Macintyre, S., and Stewart, G.S. 1997. Quorum sensing in Aeromonas hydrophila and Aeromonas salmonicida: identification of the LuxRI homologs AhyRI and AsaRI and their cognate Nacylhomoserine lactone signal molecules. Journal of Bacteriology, 179, 5271-81.

Verschuere, L., Rombaut, G., Sorgeloos, P., and Verstraete, W. 2000. Probiotic bacteria as biological control agents in aquaculture. Microbiology and Molecular Biology Reviews, 64, 655671.

Welliton, G.F., Tania, C.P., Fabricio, M.D., Frank, L., Eduardo, L., Cupertino, B., and Leandro, P. 2017. Gastrointestinal tract $\mathrm{pH}$ measurement in juveniles Pacu Piaractus mesopotamicus (Characiformes: Characidae). PanAmerican journal of Aquatic Sciences, 12,254-258.

\section{How to cite this article:}

Divya V. Haridas and Devika Pillai. 2019. Evaluation of Quorum Quenching and Probiotic Activity of Bacillus thuringiensis QQ17 Isolated from Fish Culture Pond. Int.J.Curr.Microbiol.App.Sci. 8(05): 1634-1649. doi: https://doi.org/10.20546/ijcmas.2019.805.189 